\title{
NOTAS
}

\section{El rotlo o rolde de campanillas en Mallorca}

\author{
GABRIEL LLOMPART
}

Entre los utensilios litúrgicos que hoy en día son objeto de la curiosidad de los visitantes de los templos mallorquines y que, a menudo, ponen en un brete la buena voluntad de los guías de turismo se encuentran las ruedas de campanillas instaladas sobre el presbiterio, conocidas en la isla por el rotlo, en la tierra firme catalana por el rogle y en algunas zonas del interior de la península como el rolde de campanillas.

La literatura específica existente en la actualidad sobre el más alegre y cascabelero intrumento musical del ámbito de las iglesias tradicionales, al que nos referimos en estas páginas, se reduce a un artículo del famoso historiador de Vich mosén Josep Gudiol de los años de la primera guerra mundial (1919). Desde entonces, aunque estas ruedas de gran tamaño, fijas al muro y que se voltean con manubrio, no se hayan perdido en los territorios de la antigua Corona de Aragón ${ }^{1}$, la verdad es que, las presentes limitaciones de personal auxiliar en los templos y la apatía e ignorancia consiguientes entre los parroquianos, las han reducido de hecho a una mínima expresión. En tiempos recientes sólo en la parroquia de San Lorenzo de Lérida me consta que se haya querido fundir y montar un aparejo de este tipo. Y, por cierto, que no desmerece de los modelos antiguos: suena a gloria. Téngase en cuenta que las campanillas litúrgicas han sido reducidas al silencio a menudo: comenzando por las de la elevación durante la misa y siguiendo por las de la comunión solemne de enfermos por las calles. Solamente la de las cofradías de auroros en el Levante y Sur de España sigue jugando su papel como instrumento musical popular en las parroquias rurales.

La definición más precisa que he hallado en los diccionarios o manuales del rotlo es la que trae Onofrius Povius, un pedagogo del Humanismo, en su librito Iesus. Thesaurus puerilis (1591: f.106v): «o rogle: rota multis tintinabulis affixis". Es fácil emparentarlo con el castellano rolde y derivar a ambos de rotlo, rota, rotula. Aunque hay que tener presente que su presencia y popularidad en los medios rurales hizo que desde la Edad Media se crearan vocablos locales como rodet, rodella, rodonell, etc. (Alcover y Moll 1930-1962: IX, s.v. rotlle; Griera 1947: XII, 198). Rotlo es la palabra que aparece en los primeras menciones, de $1436^{2}$

1 El Instituto Amatller de Arte Hispánico de Barcelona dispone de un útil dossier fotográfico.

2 "Guillermus de Montesono etc. discreto vicario ecclesie de Rubines etc. Ad instantiam Petri de Loberola, magistri simbulorum, vobis dicimus et mandamus quatenus, 
y de 1440 (Pollensa) ${ }^{3}$. En ambos casos se trata de apremios del vicariato episcopal para que se satisfagan los gastos de su construcción, que se mostraban remisos a pagar, bien el clero, bien el ayuntamiento que, a la sazón, corría con el importe del mobiliario comunitario.

Más curioso es el caso de un feligrés que, al hacer testamento, se declara dispuesto a obsequiar con un rolde a la parroquia de Marratxí. Se trata de cierto Joan Serra, tío del pintor Miquel d'Alcanyís II, que figura como albacea de su testamento. No cabe duda de que se trataba de una familia de buen gusto y sensibilidad. Quisiera adivinar que el rotlo fue tema de grata conversación entre tío y sobrino. Entrambos pugnaban por decorar templos a la moda de la época. Este rotlo de les esquelles era encargado en $1461^{4}$. El Llibre de Fábrica de la Seo de Mallorca menciona de paso "el rotlo del cor" en $1498^{5}$ (fig. 1).

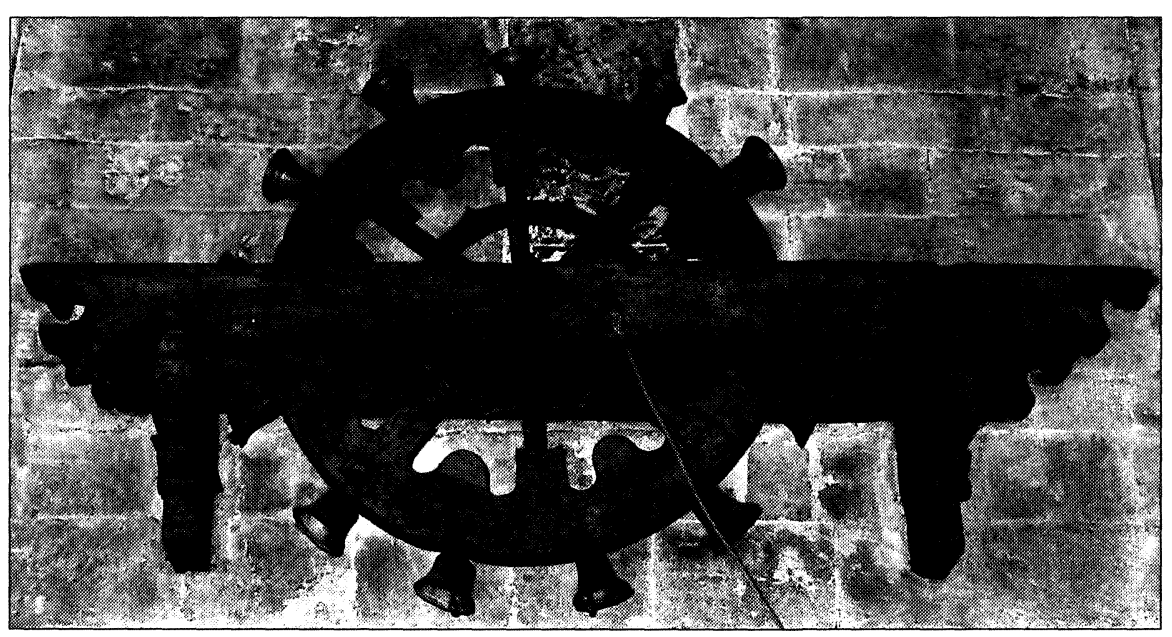

Figura 1.-Rotlo de la Catedral de Palma de Mallorca.

ex porta nostra, moneatis semel etc. discretos iuratos dicte parrochie, quatuordecim solidos, in quibus sibi tenentur ex resta maioris pecunie quantitatis, ratione cuisdam rotlo squillarum per eum facto pro decoratione dicte ecclesie, una cum expensis". Archivo Diocesano de Mallorca (=ADM). Litt. 1436, f. 53v (ad 21-3-1436).

3 "Franciscus Eximini etc. discreto vicario ecclesie Pollencie etc. Ad instanciam laurencii Marsol, paratoris Maioricarum, vobis decimus et mandamus quatenus moneatis semel etc. discretos operarios anni presentis dicte ecclesie, ut, infra decem dies, dent et solvant dicto Laurentio XXXVIII solidos, in quibus tenentur eidem pro resta maioris quantitatis pecunie, ratione squillarum cuiusdam rotlo noviter constructo in dicta ecclesia, una cum expensis". ADM. Litt. 1440 (ad 29-8-1441).

4 Iohannes Serra, de la parroquia de Marratxí. Testamento del 25-10-1461. Legado: "Item volo, ordino et mando quod morte mea sequuta heredes mei universales infrascripti teneantur facere et complere quoddam rotlo de les esquelles in ecclesia parrochiali de Marratxín. Arxiu del Regne de Mallorca (=ARM) Prot. P-363, f. 77v.

5 Archivo Capitular de Mallorca (=ACM). Ll. De fábrica 1498, f. 59. 
En los inventarios de las iglesias, a menudo, no se mencionan los rotlos por considerarse, sin duda, dada su condición de fijos, como inmuebles. Pero, de otra parte, algunos clérigos o notarios debían tener experiencia de averías, robos o pérdidas de campanillas, de donde la presencia del rotlo en otros inventarios. Así, en la iglesia de San Antonio de Viana, de Palma, se menciona en 1548 "un rotlo ab set campanetes i una campaneta com alsen Déu" ${ }^{6}$ y en Santa Fe, en 1598, aparece "un rotlo a la paret ab tretze campanetes" ${ }^{7}$. Entre las piezas más hermosas que se conservan actualmente hay que mencionar la de la parroquia de Santa Eulalia de Palma, la de la parroquia de Montuirí y la de Binissalem ${ }^{8}$. Más sencilla de factura es la de la parroquia de Bunyola (figs. 2 y 3).

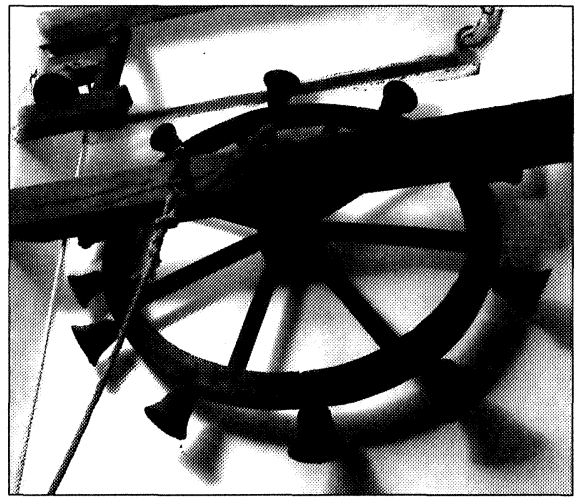

FIgURA 2.-Ejemplar de la iglesia parroquial de Bunyola.

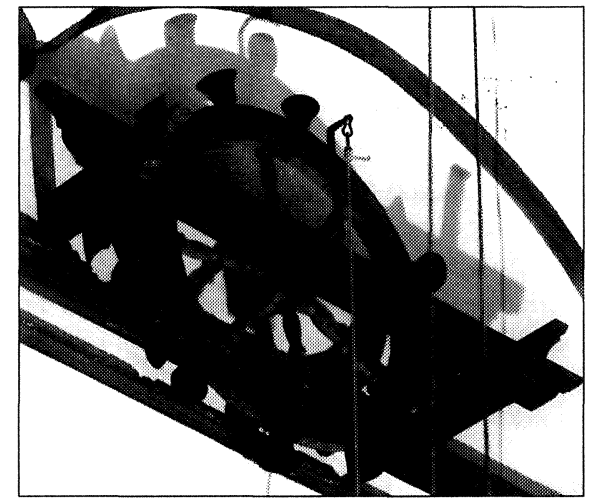

FIGURA 3.-Rotlo de la iglesia parroquial de Montuirí

De la primera mitad del siglo XVI dataría el relieve renacentista del patio del palacio que está en el número 11 de la calle Morey, en Palma de Mallorca. Hace el papel de capitel, extendiendo en torno a la rueda (de ocho campanas con manubrio figurado) dos cartelas, cuya leyenda en capitales dice así: SIRVEN / SUS / BOZES / A / DIOS / Y / MI / LENGUA / PARA / VOS. Es verdad que la rueda en cuestión es lisa, sin adornos, porque el escaso espacio de un capitel no da para más, pero también es verdad que parece apuntar a una simplificación de las grandes ruedas, como la de Binissalem que tiene aire gotizante (figs. 4 y 5$)$.

Algo posteriores pueden ser las de la catedral de Ibiza o la parroquia de Sa Pobla, con los radios de la rueda torneados que parecen argüir una traza

\footnotetext{
6 ARM. Prot. $M-878$, f. 17.

7 ARM. AH-838. Llibre des inventaris dels ornaments de la església de Santa Fe (1593s.).

8 Recuperada últimamente, mientras que las restantes se hallan in situ. Me comunica el Sr. Rafael Navarro Salom que el diámetro de la pieza es de $134 \mathrm{~cm}$. Cuenta con 13 campanillas. Piensa que fue instalada en 1689. Como se ve, por lo que antes dijimos, por entonces otras ruedas habían volteado durante siglos en el templo.
} 

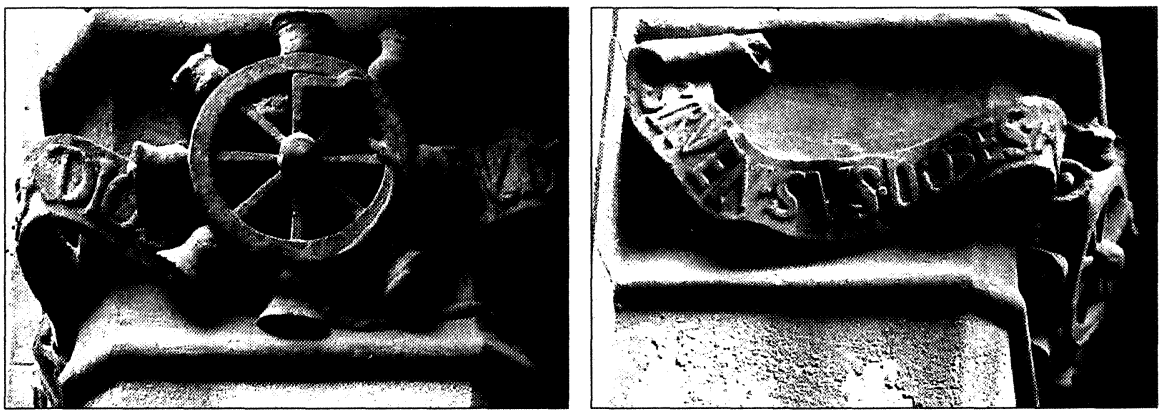

FIGURAS 4 y 5.-Relieve con la representación del rotlo.

Patio del palacio de la calle Morey n. ${ }^{\circ} 11$ (detalle).

renaciente, comparándola con alguna xilografía de la época (Michael Keinspeck. Lilium musice plane, Ulm, por Iohann Schaefler 1497) 9.

El eco popular que despertaban en la feligresía las ruedas de campanillas se detecta en el intento de expresar su sonido especial en cada caso particular, mediante locuciones homofónicas de talante humorístico que corrían en el siglo pasado y de las que he podido recoger indirectamente todavía las que siguen. Bien entendido que entonces cada parroquia contaba con su rueda, de rodaje y sonido familiar.

Parroquia de Pollensa:

Figues, olives i pa!

Figues, olives i pa!

Figues, olives i pa!

Parroquia de Santanyí:

Fava parada amb olives!

Fava parada amb olives!

Fava parada amb olives! ${ }^{10}$

Parroquia de Andraitx:

Cordes i graneres!

Cordes i graneres!

Cordes i graneres!

Parroquia de Banayalbufar: Pa, olives i vi!

$\mathrm{Pa}$, olives i vi!

$\mathrm{Pa}$, olives i vi!

Parroquia de Estallencs:

Toissa per hom!

Toissa per hom!

Toissa per hom!

9 Algunas de estas ruedas estaban guardadas en una especie de armario, como es de ver en la documentación del Instituto Amatller. E incluso en el caso de la Seo de Barcelona. El armario puede ser de traza gótica. El P. Ferreres (1910: 79) explica las circunstancias del repique de estas ruedas, que eran muy variadas, siempre correspondientes a solemnidad y alegría.

10 Recogidas de Griera (1947). 
Parroquia de Fornalutx: Segau carritxs, feis vencissos! Segau carritxs, feis vencissos! Segau carritxs, feis vencissos!

Parroquia de Petra: Qui vol filar estopa?
Qui vol filar estopa?
Qui vol filar estopa?

En la isla de Mallorca, cuando alguien sobra en un lugar es invitado a marchar diciendo esta frase figurada: "Veten a filar estopa!». Espero que el lector sea benévolo con esta disquisición y no mande al autor, como dicen en castellano, a paseo, esto es a filar estopa. Como los petrenses de antaño.

\section{BIBLIOGRAFÍA CITADA}

Alcover, ANTONi M. y Francesç DE B. Moll. 1930-1962. Diccionari Català, Valencià, Balear. Palma de Mallorca: Imp. Alcover.

FERRERES, P. 1910. Las campanas. Madrid.

Griera, ANTONi M. 1947. Tresor de la llengua, de les tradicions i de la cultura popular de Catalunya. Barcelona: Edicions Catalunya, 14 vols.

Gudiol, JOSEP. 1919. "De les campanetes litúrgiques". Vell $i$ Nou 5: 163-167.

POVIUS, ONOFRIUS. 1591. Iesus. Thesaurus puerilis. Perpignan: Tipografía Sansón Arbus.

SARTORI, PAUl. 1932. Das Buch der deutschen Glocken. Berlín: Walter de Gruyter: 135-163.

11 Recogidas en un artículo anónimo de la revista local L'Ignorància, n. ${ }^{\circ}$ 140, 11-2-1882, p. 3: “Llenguatge de ses rodelles de campanilles de ses esglésies de Mallorcan. El descubrir o inventar el lenguaje de las campanas es algo general en los países cristianos. Véase el capítulo que dedica a esto el folklorista Sartori (1932). 